\title{
Entrevista com Jan Fabre acerca da obra Mount Olympus (uma performance e de 24 horas de duração)
}

Interview with Jan Fabre about Mount Olympus (a 24hour performance)

Entrevista com Jan Fabre concedida à Wallace Freitas ${ }^{1}$ Composta em parceria com Naira Ciotti ${ }^{2}$ 


\section{Resumo}

Em decorrência da pesquisa de campo para construção da minha dissertação de mestrado, no intuito de poder compreender melhor o modus operandi do diretor transdisciplinar belga Jan Fabre, transcrevo traduzida a entrevista que me foi concedida após o término do seu trabalho teatral de 24 horas de duração - Mount Olympus. Enquanto espectador da obra apresentada em janeiro de 2016 em Antuérpia-Bélgica, questões se fizeram salientes em minhas sinapses, que se torna material para se pensar sobre o teatro contemporâneo.

Palavras-chave: Jan Fabre; Mount Olympus; Teatro Performativo

\section{Abstract}

As a result of my "field work" for the construction of my master's thesis, in order to better understand the modus operandi of the Belgian transdisciplinary director Jan Fabre, I transcribe translated the interview that was granted to me after the end of his 24-hour theatrical work - Mount Olympus. As a spectator of the work presented in January 2016 in Antwerp-Belgium, questions have become salient in my synapses, which becomes material to think about contemporary theater.

Keywords: Jan Fabre; Mount Olympus; Performative Theater

ISSN: 1414.5731

E-ISSN: 2358.6958

\footnotetext{
${ }^{1}$ Mestre em Artes Cênicas pelo Programa de Pós-Graduação em Artes Cênicas da Universidade Federal do Rio Grande do Norte (UFRN). wallace.freitas7@ gmail.com

2 Professora-performer, Dra. Universidade Federal do Rio Grande do Norte (UFRN) Departamento de Artes, atuando no Programa de Pós-Graduação em Artes Cênicas. nairaciotti@gmail.com
} 


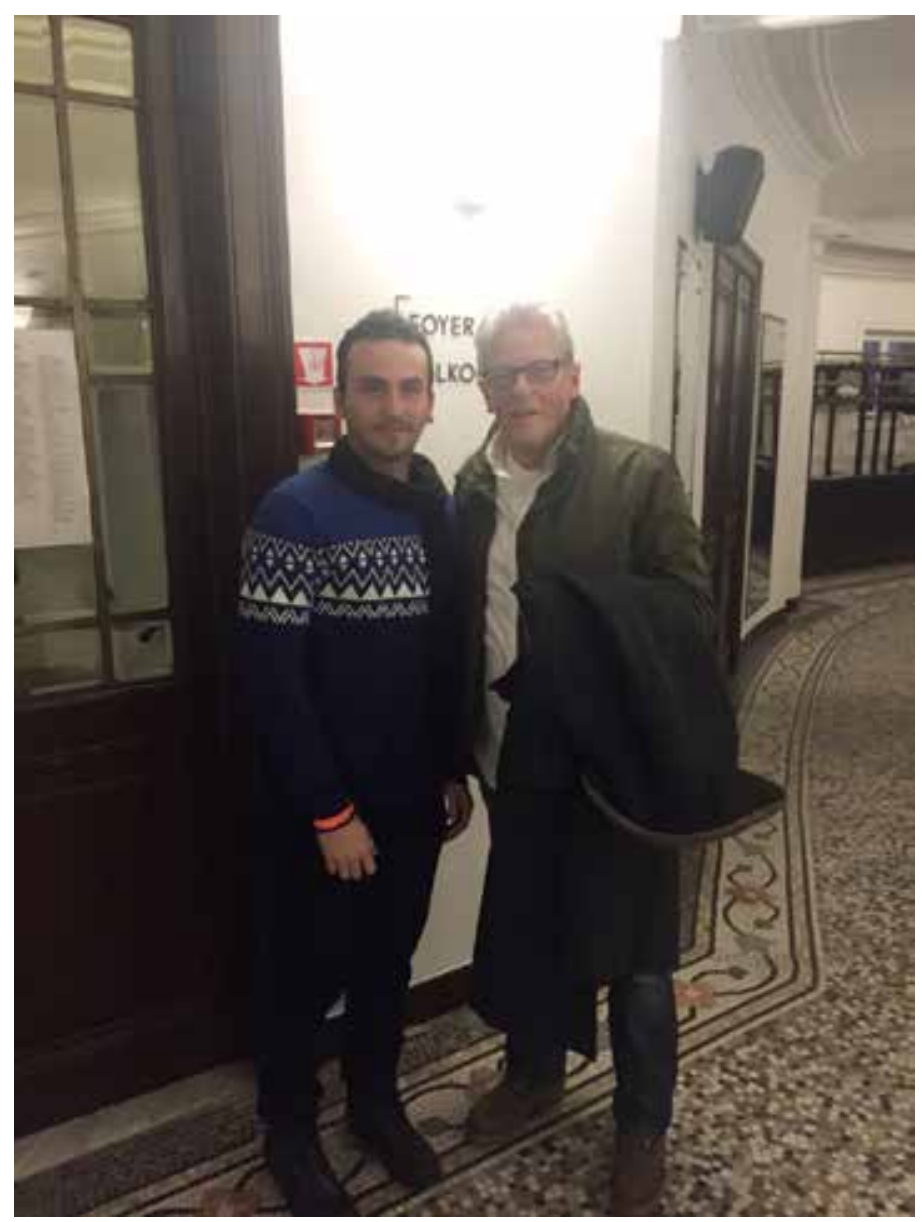

Wallace Freitas e Jan Fabre. Foto: Hareton Vechi (2016)

Jan Fabre - O diretor nasceu em 1958 na cidade de Antuérpia, na Bélgica, cidade em que ele vive até o momento, e ainda, onde mantém a sede do seu grupo de experimentação artística, o Troubleyn. No final dos anos 1970, Jan Fabre ainda jovem causou furor ao apresentar um trabalho envolvendo pacotes de dinheiros pagos como entradas do público a fim de fazer desenhos com as cinzas das cédulas queimadas. O diretor cresceu e se tornou um artista bastante versátil da cena internacional, fazendo uma ruptura com as convenções do teatro tradicional, introduzindo o conceito de "real-time performance"- às vezes chamadas de "instalações vivas" - explorando desde a possibilidade de coreografias enérgicas e rígidas à improvisação. Depois de sua produção histórica de oito horas This is theatre like it was to be expected and foreseen (1982) e a produção de quatro horas The power of theatrical madness (1984), ele elevou seu trabalho a um nível monumental e digno de pesquisa, Mount Olympus - uma glorificação do culto à tragédia- uma performance de 24 horas (2015). ${ }^{3}$

\section{MOUNT OLYMPUS}

Mount Olympus foi concebida com o intuito de glorificar o culto à tragédia, performada em 24 horas de duração ininterrupta, traduzindo-se como um grande 
pedaço da história mergulhada em um mar do tempo. É o tempo da humanidade, tempo do nascimento da tragédia, da descida ao inferno e da erupção do mal que incessantemente insiste em vomitar cinzas. Partindo de um lugar reprodutor de arrogâncias, cegueira e todos os desejos que dominam os homens (dos mitos gregos aos atuais).

Como em um ciclo interminável, o homem constantemente tropeça em mandamentos "divinos", caindo, e assim, arrastando gerações no tempo. Simultaneamente distantes e próximos, reconhecemos contornos de histórias e personagens extraídos da tragédia grega. Esses seres ou espectros têm suas falhas expostas por Fabre, sendo deixados em frangalhos, espancados pela violência e riso homéricos, numa espécie de fervoroso êxtase.

Observa Lehmann $(2014)^{4}$ que o projeto de Jan Fabre está imbuído de tudo aquilo que é trágico, com temas míticos mais amplos: gestos rituais (como enterros com sua lamentação e consolação), o êxtase do desejo, lutas e dor física, forças e fraquezas, poses momentâneas de vitória e a experiência da catastrófica derrota, morte, animalidade versus humanidade, humanos e seus deuses, e, intercâmbio de gêneros (estátuas masculinas se transformando em mulheres reais...).
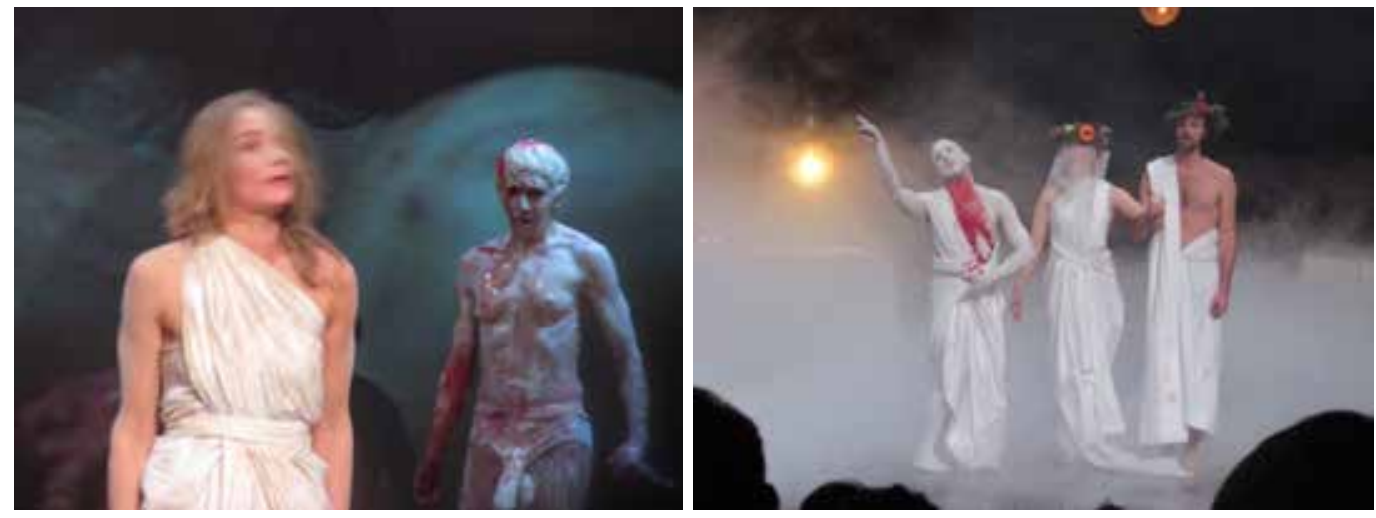

Mount Olympus. Foto: Wallace Freitas, 2016.

Eles se inspiram a partir da ideia de retaliações e vinganças, feito animais chifrudos que batem seus chifres uns nos outros até o sangue jorrar. Como também, igualmente se alimentam do desejo e do amor que sempre nos conectam, e, do êxtase que nos deixa em frenesi. É possível pensar que a tragédia continua sendo tangível no teatro contemporâneo: a carne rasgada, os órgãos, o louro, as pétalas, o vapor, o solo, pedaços de sonhos, o som do bater dos metais e o cheiro do sangue coagulado.

Seria interminável descrever parte por parte desse projeto monumental, relatar as nuances e cheiros, os textos colocados de forma repetitiva, a exposição de alguns dos vários mitos gregos de forma escancarada e não clássica (aristoté(ica) ${ }^{5}$, ou resumi-lo. O espetáculo não está imbuído de sínteses ou resoluções de seus atos. As transições vão ocorrendo, correndo, cansando e extasiando tanto o performer quanto o espectador. Penso, pois, na ideia de fragmentos.

\footnotetext{
${ }^{4}$ Tradução indireta das notas de observação de Lehmann ao assistir o processo de construção do espetáculo em Antuérpia. Disponível em < http://janfabre.be/troubleyn/wp-content/uploads/2014/11/Notes-from-Antwerp.pdf >. Acesso 12 jun. 2016.

${ }^{5}$ Patrice Pavis em seu dicionário vai colocar o seguinte: termo usado por Brecht e retomado pela crítica para designar uma dramaturgia que se vale de Aristóteles, dramaturgia baseada na ilusão e na identificação. O termo tornou-se sinônimo de teatro dramático, teatro ilusionista ou teatro da identificação. (Pavis, 2008, p. 24)
} 
Posso dizer que os vestígios da tragédia, especificamente nesta obra de Fabre, me levam para inquietações irresistíveis: $O$ que é tempo no teatro? $O$ que acontece quando o tempo é estirado até que ele relaxe e seja desvendado? É uma espécie de alucinação? Um sonho? O que será que acontece quando chafurdamos o "pântano da insônia"?6

A obra Mount Olympus possui quase as mesmas características que constatei em seu famoso trabalho de 2012 - The Power of Theatrical Madness: a repetição enquanto ingrediente marcante; o treinamento corporal rígido e disciplinado ou uniformização em algumas cenas; o caos e a desobediência às "regras"; o tempo dilatado e duração (nesse caso, o mais longo de todos os trabalhos); a referência à história do teatro ou de como se pensava o teatro (na Grécia, neste caso); o corpo constantemente como elemento primal; as simetrias e desordens. Enfim, tudo autentica ou torna reconhecível que a obra é, de fato, um trabalho de Fabre.

Fabre e seus atores imergem implacavelmente nesses mitos e imagens do corpo da antiguidade, mas o que eles estão criando sobre isso não se cristaliza no classicismo, nem de longe uma imitação do mundo antigo. $\mathrm{O}$ trabalho dos atores, assim como o projeto por completo, se direciona livremente - desinibido pela convencionalização cliché da arte antiga - direcionado para o espaço imaginário que foi criado pelos antigos textos da tragédia. São gerados por imagens e sentidos mitológicos - os rituais, os gestos de sacrifício, na desmedida experiência da dor, a pose do triunfo e sua efemeridade (Lehmann, 2014). ${ }^{7}$

O local do espetáculo, o Teatro Toneelhuis em Antuérpia-Bélgica, foi devidamente preparado para os espectadores. Foram instaladas uma gama de camas nos corredores, restaurante e bar dentro do próprio teatro, aberto em todo o tempo da performance, para que as 24 horas não fossem interrompidas e sim compartilhadas.

Minha estadia na cidade durou pouco tempo, por isso, a possibilidade de encontro com Fabre se mostrava algo difícil de ocorrer - ele só existia para a execução do espetáculo e não parava em lugar algum. Entretanto, no final do espetáculo - já um tanto cansado - acabei por esbarrar com Jan Fabre num corredor deserto, pelo semblante, ele não descansava há uma semana devido os preparativos para a apresentação. Falei rapidamente da minha pesquisa e que gostaria de conversar melhor com ele, fomos enquadrados por pessoas que, aos poucos, enchiam esse pequeno espaço rápido de diálogo e não foi possível dar continuidade à conversa.

Devido a correria, o avisei que no dia seguinte estaria partindo e acreditava não ser mais possível nos encontrarmos para essa conversa (já que a oportunidade que tivemos logo se dissolveu). Tiramos uma foto, e por fim, comentei que enviaria uma carta com algumas perguntas, cordialmente ele disse que me responderia com muito prazer. Dadas as circunstâncias de tempo, acabei por adotar o procedimento, e enviei cartas também para alguns performers para que me respondessem quando tivessem maior disponibilidade.

\footnotetext{
${ }^{6}$ Os três primeiro parágrafos desta secção são uma tradução e apropriação (ou seja, uma mistura de tradução indireta com minhas percepções) de um pequeno texto encontrado no site do diretor, sobre a obra. Disponível em: < http://janfabre.be/troubleyn/eng/ performances/mount-olympus >. Acesso em: 10 ago. 2016.

${ }^{7}$ Tradução das notas de observação de Lehmann ao assistir o processo de construção do espetáculo em Antuérpia. Disponível em < http://janfabre.be/troubleyn/wp-content/uploads/2014/11/Notes-from-Antwerp.pdf >. Acesso em: 12 jun. 2016.
} 
Sendo assim, os textos enxertados aqui, são traduções da carta enviada (via e-mail) à Fabre. Assumo que as perguntas surgiram depois do espetáculo apresentado em janeiro de 2016 e do desejo de tentar compreender mais esse teatro, o qual dialoga fortemente com a performance e outras linguagens artísticas.

Informo ainda, que, a partir do momento que me coloco na condição de tradutor, ou ainda, que mudo ou faço transferências de uma língua para outra, o teor do texto acaba tomando um novo formato, não que exista uma distância colossal entre o original e a tradução (e pode existir também), mas é previsto que uma tradução possa perder algum mínimo valor semântico da língua em que foi falada.

Assumo que existe uma tentativa de manter-me fiel em toda a tradução, inclusive preservando as várias falas fragmentadas, como se não estivessem dialogando com a frase anterior do diretor. Texto não linear, ou fragmentado, é algo que atravessa os trabalhos do diretor, e talvez isso seja tão enraizado, que em uma simples entrevista, tal característica se faça presente nas respostas do mesmo.

\section{Por que a Tragédia Grega?}

Quando você observa meus trabalhos visuais e escritos nos últimos 30 anos, você consegue perceber que a matriz grega sempre esteve lá (por exemplo, Prometheus enquanto tema da escultura The man who gives fire, ou ainda, as esculturas de besouros (scarabees) e desenhos em torno do mito de Sísifo).

Em um nível mais prático, eu comecei a me concentrar neste projeto há 3 anos juntamente com o teórico de teatro Hans-Thies Lehmann, e ainda, em companhia de minha fiel dramaturga, Maria Martens. Eu escrevi diferentes textos sobre sonhos, pesadelos e insônia. Para mim existe uma profunda ligação entre as tragédias e os sonhos, porque todas as tragédias estão sempre voltando como predições através dos sonhos. A sociedade grega acreditava muito na ideia de visões.

Eu pedi a Jeroen Olyslaegers - que é um respeitado escritor na Bélgica - para reescrever as tragédias. Enquanto pano de fundo, eu escolhi as tragédias familiares, onde você vê: poder, classe e batalhas sexuais.

Nós temos ensaiado essa performance por 12 meses, todos os dias das 11 horas da manhã até 01 hora da madrugada, com 27 performers, os quais, nesse período, não foram vistos ou fizeram coisas na maioria dos teatros "oficiais" da Europa, continuando no trabalho mesmo com todas as dificuldades do grupo.

Em Mount Olympus eu estou olhando novamente para a ponte entre a performance e o teatro. Existe também a influência das 24 horas - como esse longo tempo irá influenciar a performance no palco, como os textos e as ações físicas serão contaminadas por esse tempo?

\section{Você acha que a tragédia grega ainda é válida para falar de coração para co- ração para o público que atualmente vai ao teatro?}

Eu tenho fé na função original do teatro: um lugar onde você pode refletir sobre sua própria vida através de histórias míticas. Adultério, estupro, assassinato, guerra, traição, vingança, inveja, competição e rivalidade... Os temas que preenchem os jornais atualmente não diferem dos assuntos que afetavam os gregos... Mount Olympus resgata velhas histórias numa composição diferente e confere-lhes novos significados. 
Na sociedade atual nós possuímos a solução para qualquer problema, no entanto, na sociedade grega, a ideia de conflito era celebrada. Para mim, essa ideia incorpora toda a essência do drama: é tudo sobre conflitos. Eu sou um artista que celebra conflitos, seja em meus trabalhos visuais, como em meus escritos e minhas performances. A partir do conflito eu conduzo meu próprio cérebro a pensar de uma forma diferente.

O performer carrega o conflito em seu próprio corpo, o drama está lá. Você ainda enxerga todas essas tragédias gregas acontecendo em nossa sociedade agora. Pense sobre a história de Medeia: uma mãe que prefere matar seus filhos para impedir de vê-los crescer em uma sociedade patriarcal. Isso é uma metáfora para como uma mãe síria poderia se sentir nos dias de hoje: ela provavelmente iria preferir matar seus filhos a vê-los caindo nas mãos do Estado Islâmico.

\section{Por que 24 horas? Como você entende o tempo em seu trabalho?}

$\mathrm{Na}$ Grécia antiga, os habitantes de Atenas muitas vezes se reuniam no Teatro de Dionísio ao pé da Acrópole para assistir as peças de teatro que duravam o dia inteiro. Tragédias, sátiras e comédias, se alternando na passagem de uma história para outra. Em torno do teatro havia uma atmosfera festiva com várias oportunidades para o público conhecer um ao outro, fosse entre alguma refeição ou bebidas. Na verdadeira tradição dramática grega estas performances duravam 24 horas, um dia e uma noite.

Tempo é e sempre foi um fator essencial em meu trabalho. Tempo como uma pedra de construção arquitetônica; tempo como uma rede de repetição, e pela repetição, a mudança de conteúdo. É através das regras do tempo no teatro que o público se entrega a um outro tipo de tempo. Nós vivemos com toda essa nova "mídia social", Facebook, Twitter, todo mundo possui um smartphone... Os espectadores são levados ao longo de um percurso.

Eu mostro-lhes imagens do homem que eles vêm reprimindo ou esquecendo. Eu faço um apelo a seus impulsos violentos, aos seus sonhos e seus desejos. Eu instigo um processo de mudança. Não somente a metamorfose do ator, mas também do espectador. Ao confrontar esse profundo sofrimento, a mente vai sendo purificada. Meu teatro é um tipo de ritual de purificação. Ao compartilhar uma experiência de 24 horas enquanto tempo real, com outras pessoas, isso transforma-se em algo muito espiritual.

\section{Como você entende a relação do teatro com as artes visuais? Poderia eu chamar seu trabalho de "Teatro Híbrido"?}

Eu comecei minha carreira artística como um artista da performance. No meu trabalho há constantemente elementos e ideias que crescem em direção uma da outra. Volto no tempo, olho para o futuro, atravesso ou apenas descanso uma ideia antes deixá-la tomar nova forma. Eu sempre fui consciente do fenômeno "consiliência" através de alguém que me inspirou fortemente: Edward $O$. Wilson, entomologista, filósofo e biólogo. Ele use esse termo em seu livro Consilience, the Unity of Knowledge e eu tenho sempre sido um tipo de artista "consiliente". Nem artista devoto da mídia nem artista híbrido. Eu sempre fiz teatro, fiz performances... estas são todas as consiliências entrelaçadas dentro de todas estas diferentes disciplinas, mas com respeito às leis específicas de cada meio. 


\section{Você poderia descrever um pouco sobre o processo criativo do Mount Olym- pus?}

Meus projetos têm a tendência de se desenvolverem por um longo período de tempo. Eu sempre tenho um enxerto de papel, esboços, pequenos pedaços de texto e desenhos espalhados sobre minha mesa. E no curso de vários anos algumas dessas ideias vão se movendo em torno uma da outra.

Perceba que, o método de trabalho desenvolvido na minha sala de ensaio teatral é muito mais próximo ao que acontece no cenário da dança contemporânea, do que o que acontece em média no Flamengo ou modelo "texto-base" europeu enquanto direção.

Nós não começamos com um clássico ou texto contemporâneo escrito por um autor externo, nosso departamento dramatúrgico não faz um estudo preliminar de um texto e eles também não possuem todas as respostas. O elenco também não é colocado diretamente junto em partes predeterminadas de uma peça. Normalmente, um ator ou bailarino empenhado irá receber um pequeno pedaço de texto para começar o processo de trabalho, um texto que irá fazer crescer muito mais dúvidas do que respostas.

Isso não significa que começamos nossos processos de trabalho sem nenhuma preparação, muito pelo contrário. Mas tudo é válido e nada é impossível. O ponto de partida pode ser qualquer coisa: o título, um tema, uma suposição filosófica ou conceito, alguns dos meus próprios textos teatrais... Usando isto, nós começamos a procurar todo tipo de material, examinamos todas as formas de abordagem, e ainda, testamos todas as possibilidades no que diz respeito ao conteúdo.

Ao longo dos anos a minha paixão pela entomologia cresceu. Isto se tornou uma inspiração tanto para as minhas obras de arte gráficas quanto para as minhas produções teatrais. Eu regularmente venho utilizando o conhecimento advindo sobre o senso territorial dos insetos, assim como a organização espacial, como exemplo para topografia de minhas produções no palco. E corriqueiramente eu copio o comportamento e movimento dos insetos, formigas e aranhas como orientação para os movimentos dos atores e bailarinos. Também já utilizei muitos animais vivos no palco.

Depois de certo tempo, meu material vai se impor a mim novamente, na forma de novas questões. Eu aprendo muito a partir desses questionamentos que eu minimamente entendo. E claro que, existe leitura, pesquisa, "exame de pensamentos". Eu gosto de trabalhar com exercícios. Para mim, improvisação significa principalmente abrir o espaço para o contexto da investigação experimentando a liberdade da imaginação. Eu gasto bastante tempo com isso, porque eu gosto de planejar detalhadamente a cena. Durante as improvisações a concentração mental e física é lapidada.

Nós não exploramos somente o material, exploramos também uns aos outros. À medida que pesquisamos o comportamento humano e animal, eu passo a conhecer seus impulsos primários pessoais e descubro quais são suas capacidades instintivas. Para o ator, é também uma maneira de dominar a economia de movimento: eles aprendem como desenvolver calma em êxtase e raiva concentrada.

Dessa forma nós damos uma chance a ironia ou a tragicomédia. Mas, principalmente, a improvisação levada ao palco em minhas performances, enquanto momento de exploração. Uma exploração de todo o material possível e uma exploração também entre os atores e dançarinos. Descobrindo e se respeitando um ao outro. Apenas em razão do respeito mútuo e uma relação de confiança ininterrupta é que eles podem se enfrentar nesse extremo campo de batalha do amor que é o meu teatro.

Uma série dessas improvisações retornam em todos os meus trabalhos em pro- 
cesso. Elas são a base para minhas pesquisas de laboratório; são a essência da minha "gramática". Por exemplo, existe o Sisyphus-exercise: ações físicas que são realizadas para o desgaste e estrago do tempo. O que acontece dentro e sobre o seu corpo quando você tem que ficar empurrando a mesma pedra montanha acima de novo e de novo? Qual é o efeito da exaustão em seus músculos, tendões, pele e concentração?

Minha dramaturga, Maria Martens, com quem eu tenho trabalhado junto há mais de 30 anos, escreve todas as improvisações em seu caderno. É uma memória adicional próxima a mim e aos meus desenhos. Como uma testemunha para os locais que estive durante os ensaios. Depois de semanas ou meses de improvisação, a possibilidade de cenas e temas começa a se tornar mais clara e começamos então a poli-los e fazer resumos, apontando possíveis estruturas de significados.

\section{Qual o papel dos artistas no processo criativo?}

Há muito tempo atrás, em um jornal, eu parafraseei Sacher-Masoch sobre a relação entre atores e um diretor: "eu sou pego por minha palavra de honra de ser o escravo dos meus atores e atrizes, exatamente da forma como ele ou ela exige de mim. E de me submeter, sem qualquer oposição a qualquer coisa que ele ou ela imponha a mim". Mas o reverso disso é verdade também, "eu sou limitado por minha palavra de honra de ser o escravo do meu diretor, exatamente da maneira que ele exige de mim. E de me submeter, sem qualquer oposição a qualquer coisa que ele imponha a mim" (02 de Agosto de 1980).

Você ainda deve olhar para o meu relacionamento com os atores e dançarinos nessa direção. Eu darei alguns exercícios de improvisação, geralmente com o intuito de ver até onde eles vão. Isso falando no geral, claro. Há sempre uma qualidade cinética, a inteligência individual, o coração e a alma dos atores e dançarinos que dão à performance o seu lustre. Tudo isso é imprevisível e dificilmente pode ser encenado. São eles que determinam a verdadeira qualidade da performance.

Então, durante o processo de trabalho eu me faço constantemente a seguinte questão: como eu posso dar aos colaboradores que trabalham comigo, liberdade suficiente para que eles cheguem a um resultado alcançado através deles mesmos e que sempre esteve ali, em suas próprias mãos? E ao mesmo tempo eu preciso encontrar um equilíbrio certo, onde eu possa intervir em momentos apropriados e realizar o que eu tenho em mente.

Eu acredito que dando aos atores certa quantidade de liberdade, eles serão hábeis a descobrirem suas próprias capacidades e assim executar seu próprio curso com o material de trabalho. E, em seguida, em certo ponto, eles precisarão condensar isso, corrigi-lo em uma estrutura específica, ou até mesmo em um território.

Recebido em: 18/04/2017

Aprovado em: 19/05/2017 